\title{
Research Civil Aircraft Model (RCAM) Dengan Metode Dinamis 6 Derajat Kebebasan Menggunakan MATLAB
}

\section{( Research Civil Aircraft Model (RCAM) With 6 Degrees Of Freedom Dynamic Method Using MATLAB )}

\author{
Aulia Widya Prameswari*1, Arief Suryadi Satyawan ${ }^{2}$, Denden Mohamad Ariffin ${ }^{3}$ \\ ${ }^{1}$ Universitas Nurtanio \\ E-mail: aulia.tp18@student.unnur.ac.id \\ ${ }^{2}$ Badan Riset dan Inovasi Nasional, Universitas Jambi \\ E-mail: arief.suryadi@akane.waseda.jp \\ ${ }^{3}$ Prodi Teknik Aeronautika Pertahanan, Akademi Angkatan Udara, Yogyakarta \\ E-mail:denden8552@aau.ac.id
}

\begin{abstract}
The Aircraft Model is an attempt to create or simulate an actual aircraft and this model can be called the Research Civil Aircraft Model (RCAM), which is a twin-engine civil aircraft model developed by the Group for Aeronautical Research and Technology in Europe (GARTEUR). This aircraft model is similar to the Boeing 757-200. Research Civil Aircraft Model created using 6 degrees of freedom. 6 degrees of freedom consist of 3 translations, namely 3 degrees for Cartesian coordinates on the axis $(x, y, z)$ and 3 rotations, namely 3 degrees (pitch, roll, and yaw) which are used to control surface deflection and throttle position. To create a model, parameters are needed, namely the parameters of the mass of the aircraft and the parameters of the aero chord and also the CoG (Center of Gravity) of an aircraft. The algorithm entered comes from control limits/Saturation, Intermediate Variables, Force Coefficients, Moment Coefficients, Propulsion Effects, Gravity Effects until finally simulated using "Simulink" in MATLAB. In order to produce not only graphics, animation is needed to see the attitude of the aircraft, so 3D Animation is used in MATLAB. The results of this civil aircraft modeling are to see a simulation of the stability of the ailerons, rudders, elevators, and throttles when the plane is flying. The results can vary because in $3 D$ Animation, the plane can be controlled from the plane's attitude when tilted right or left and also when the plane rolls. With this, it is hoped that the simulation can be effective in seeing the actual results when the plane is flying and can also be used as a simulator before the plane takes off.
\end{abstract}

Keywords-MATLAB, 6 Degree of Freedom, Simulink, 3D Animation, Surface Deflection

Abstrak-Model Pesawat merupakan suatu usaha untuk menciptakan atau membuat simulasi pesawat yang sebenarnya dan model ini bisa disebut Research Civil Aircraft Model (RCAM), yaitu model pesawat sipil bermesin ganda yang dikembangkan oleh Group for Aeronautical Riset dan Teknologi di Eropa (GARTEUR). Model pesawat ini mirip dengan Boeing 757-200. Research Civil Aircraft Model yang dibuat menggunakan 6 derajat kebebasan. 6 derajat kebebasan terdiri dari 3 translasi yaitu 3 derajat untuk koordinat kartesian pada sumbu $(x, y, z)$ dan 3 rotasi yaitu 3 derajat (pitch, roll, dan yaw) yang digunakan untuk mengontrol defleksi surface dan posisi throttle. Untuk membuat model, diperlukan parameter, yaitu parameter dari massa pesawat dan parameter dari chord aero dan juga CoG (Center of Gravity) dari suatu pesawat. Algoritma yang dimasukkan berasal dari control limits/Saturasi, Variabel Intermediate, Koefisien Force, Koefisien Momen, Efek Propulsi, 
Efek Gravitasi hingga akhirnya disimulasikan menggunakan "Simulink" pada MATLAB. Agar yang dihasilkan tidak hanya grafik maka diperlukannya animasi untuk melihat sikap pesawat sehingga digunakanlah 3D Animation pada MATLAB. Hasil dari permodelan pesawat sipil ini untuk melihat simulasi stabilitas dari aileron, rudder, elevator, dan throttle saat pesawat itu terbang. Hasil yang ada dapat berubah-ubah karena pada 3D Animation, pesawat dapat dikendalikan dari sikap pesawat saat miring kanan atau kiri dan juga saat pesawat berguling. Dengan adanya hal ini diharapkan simulasi tersebut bisa effective untuk melihat hasil yang sebenarnya saat pesawat terbang dan juga bisa dijadikan untuk simulator sebelum pesawat tersebut lepas landas.

Kata Kunci-MATLAB, 6 Derajat Kebebasan, Simulink, Animasi 3D, Defleksi Surface

\section{Pendahuluan}

$\mathrm{P}$ enerbangan di dunia mengalami perubahan yang cukup pesat, teknologi yang dikembangkan selalu mengalami pembaharuan. Dalam teknologi pesawat sistem selalu diperbarui dengan tujuan agar jalannya penerbangan dapat berjalan dengan lancar dalam kondisi apapun. Dalam hal ini lah perlu adanya simulasi selama penerbangan yaitu dengan mengimplementasikan suatu program yang dapat menghasilkan simulasi yang tepat dan juga effisien dalam penerbangan. Hal yang penting yaitu melihat bagaimana stabilitas gerak dari pesawat yang terlihat dari aileron, elevator, rudder, dan juga throttle karena ketika dapat melihat stabilitasnya maka dengan mudah menentukan posisi yang benar saat pesawat terbang. Dalam Tantangan Desain GARTEUR tentang Robust Flight Control (1995-1997) 18 tim dari 7 negara Eropa menyelidiki penerapan modern konsep kontrol untuk mengembangkan robust kontrol ketinggian GARTEUR yaitu Kelompok Penelitian Aeronautika dan Teknologi di Eropa sistem. Salah satu tolok ukur yang diselesaikan di sana adalah desain autopilot untuk Research Civil Aircraft Model (RCAM), yang datanya telah disediakan oleh Aerospatiale [1]. Dengan begitu RCAM (Research Civil Aircraft Model) adalah salah satu cara untuk dapat melihat model pesawat yang dibuat mirip seperti pesawat komersial twin-engine Boeing 757-200[2]. RCAM (Research Civil Aircraft Model) dibuat melalui metode 6 derajat kebebasan, 6 derajat kebebasan terdiri dari 3 translasi yaitu 3 derajat untuk koordinat kartesian pada sumbu (x,y,z) dan 3 rotasi yaitu 3 derajat (pitch, roll, dan yaw) yang digunakan untuk mengontrol defleksi surface dan posisi throttle. Untuk membuat model, diperlukan parameter, yaitu parameter dari massa pesawat $(\mathrm{kg})$, parameter dari chord aerodynamic ( $\bar{c}$ ) dan juga CoG (Center of Gravity) yaitu Dely, Delx dan Delz dari suatu pesawat.[1]

\section{LANDASAN TEORI}

\section{A. MATLAB}

MATLAB adalah produk dari Math Works, INC. dan merupakan perangkat lunak yang dirancang khusus untuk komputasi ilmiah dan teknik. Pada perangkat lunak MATLAB dapat mengintegrasikan ilustrasi grafis dengan perhitungan numerik yang tepat, mudah digunakan, dan komprehensif untuk melakukan berbagai jenis perhitungan dan visualisasi. MATLAB telah terbukti menjadi alat yang sangat fleksibel dan berguna untuk memecahkan masalah dibanyak bidang, seperti matematika, algoritma, pemodelan, simulasi, analisa data, grafik untuk ilmiah dan teknik, pengembangan aplikasi dan membuat sistem antar muka.[3] 


\section{B. SIMULINK}

Simulink merupakan bagian tambahan dari software MATLAB (Mathworks Inc.). Simulink dapat digunakan sebagai sarana pemodelan, simulasi dan analisis dari sistem dinamik dengan menggunakan antarmuka grafis (GUI). Simulink terdiri dari beberapa kumpulan toolbox yang dapat digunakan untuk analisis sistem linier dan non-linier. Beberapa library yang sering digunakan dalam sistem kontrol antara lain math, sinks, dan sources. Simulink adalah suatu paket perangkat lunak yang terintegrasi dengan Matlab untuk melakukan simulasi sistem dinamik dengan metode grafis. Dengan Simulink, suatu masalah teknikal atau sains dapat dibuat dalam bentuk diagram blok dan panah-panah yang menggambarkan aliran sinyal dan fungsi-fungsi yang terlibat dalam suatu sistem dinamik. Dalam modul ini akan diperkenalkan juga cara membuat model system dinamik, pemodelan system control dan penerapannya dalam bidang teknik dan sains.[4]

\section{SIMULINK ANIMASI 3D}

Simulink 3D Animation menghubungkan model Simulink dan algoritma MATLAB ke objek grafik 3D dalam adegan realitas virtual. Dapat menganimasikan dunia virtual dengan mengubah posisi, rotasi, skala, dan properti objek lainnya selama simulasi desktop atau real-time. Dapat juga merasakan tabrakan dan peristiwa lain di dunia virtual dan memasukkannya kembali ke dalam algoritma MATLAB dan Simulink. Video dari kamera virtual dapat dialirkan ke Simulink untuk diproses lebih lanjut. Simulink 3D Animation menyertakan editor dan viewer untuk rendering dan interaksi dengan adegan virtual. Dengan Editor Dunia 3D, Anda dapat mengimpor format file CAD dan URDF serta adegan detail penulis yang dikumpulkan dari objek 3D. Dunia 3D dapat dilihat secara mendalam menggunakan penglihatan stereoskopik. Anda dapat menggabungkan beberapa tampilan adegan 3D di dalam figur MATLAB, dan berinteraksi dengan dunia virtual menggunakan joystick umpan balik paksa, mouse ruang angkasa, atau perangkat keras lainnya. Simulink 3D Animation mendukung X3D, format file standar ISO dan arsitektur run-time untuk mewakili dan berkomunikasi dengan adegan dan objek 3D. [6]

\section{6 DERAJAT KEBEBASAN}

Pesawat terbang merupakan sarana transportasi udara yang memiliki enam derajat kebebasan gerak (DOF) yaitu sistem gerak yang dikontrol oleh aileron, elevator dan rudder. Gerak longitudinal pesawat terbang dikontrol oleh sistem elevator. Sistem pengendalian gerak pesawat terbang dengan mempertimbangkan adanya suatu noise, sehingga dibutuhkan estimator yang digunakan untuk mengestimasi gerak pesawat terbang[5]. 6 derajat kebebasan terdiri dari 3 translasi yaitu 3 derajat untuk koordinat kartesian pada sumbu (x,y,z) dan 3 rotasi yaitu 3 derajat (pitch, roll, dan yaw) yang digunakan untuk mengontrol defleksi surface dan posisi throttle.

\section{Model YANG DiUSULKAN}

Tahapan penelitian seperti pada Tabel 1. Diagram Alir, tahapan yang dilakukan untuk membuat RCAM (Research Civil Aircraft Model) seperti pada Gambar 1. 
TABEL I

TAHAPAN PENELITIAN

\begin{tabular}{|l|l|l|l|}
\hline No & \multicolumn{1}{|c|}{ Tahapan } & \multicolumn{1}{|c|}{ Metoda } & \multicolumn{1}{c|}{ Hasil } \\
\hline 1 & Studi Literatur & $\begin{array}{l}\text { 1. Survei Internet } \\
\text { 2. Studi Jurnal }\end{array}$ & $\begin{array}{l}\text { Pemahaman : } \\
\text { 1. Mengenai Reasearch Civil Aircraft } \\
\text { Model (RCAM) } \\
\text { 2. Pemrogaman MATLAB }\end{array}$ \\
\hline 2 & $\begin{array}{l}\text { Memasukkan } \\
\text { data nilai dan } \\
\text { rumus ke } \\
\text { algoritma }\end{array}$ & $\begin{array}{l}\text { Menggunakan software } \\
\text { pemrograman } \\
\text { MATLAB }\end{array}$ & $\begin{array}{l}\text { 1. Pemrogaman dengan Bahasa } \\
\text { MATLAB } \\
\text { Desain Software RCAM }\end{array}$ \\
\hline 3 & $\begin{array}{l}\text { Desain Pada } \\
\text { Simulink }\end{array}$ & $\begin{array}{l}\text { Menggunakan software } \\
\text { pemrograman } \\
\text { MATLAB }\end{array}$ & $\begin{array}{l}\text { Block Diagram, RCAM input sampai RCAM } \\
\text { Output }\end{array}$ \\
\hline 4 & $\begin{array}{l}\text { Running Hasil } \\
\text { Simulink }\end{array}$ & $\begin{array}{l}\text { Menggunakan software } \\
\text { pemrograman } \\
\text { MATLAB }\end{array}$ & $\begin{array}{l}\text { Animasi Simulink 3D bergerak sesuai } \\
\text { dengan masukkan data yang ada }\end{array}$ \\
\hline 5 & $\begin{array}{l}\text { Melakukan } \\
\text { Analisis }\end{array}$ & $\begin{array}{l}\text { Analisis Kuantitatif dan } \\
\text { Kualitatif }\end{array}$ & Data dan Kesimpulan Implementasi \\
\hline
\end{tabular}

Diagram Alir, tahapan yang dilakukan untuk membuat RCAM (Research Civil Aircraft Model)

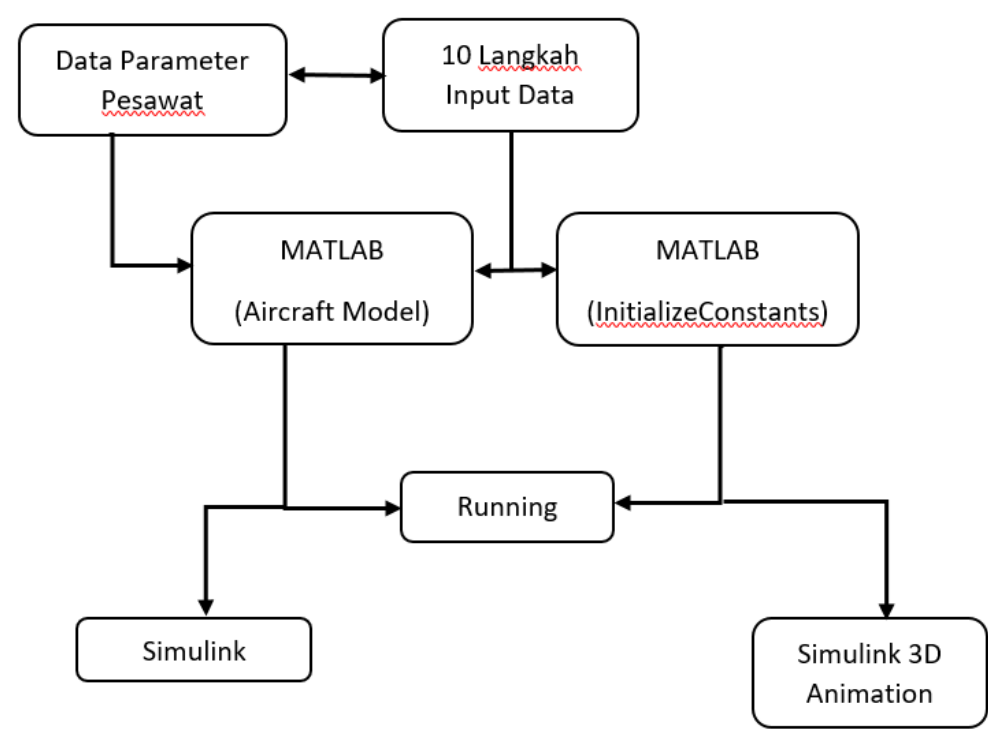

Gambar 1. Diagram Alir Penelitian

\section{IMPLEMENTASI MODEL DAN PEMBAHASAN}

Dalam mengimplementasikan suatu model pesawat diperlukannya data untuk mendukung proses pemodelan, dari data inilah bisa diubah menjadi algoritma dalam software MATLAB. Tabel 2 berikut adalah data parameter dari suatu pesawat : 
TABEL II

PARAMETER PESAWAT

\begin{tabular}{|l|l|l|l|}
\hline \multicolumn{1}{|c|}{ Simbol } & \multicolumn{1}{|c|}{ Nama Parameter } & \multicolumn{1}{c|}{ Arti Parameter } & Nilai Parameter \\
\hline M & Mass & Berat Total Pesawat & $120.000 \mathrm{~kg}$ \\
\hline $\bar{c}$ & Cbar & Mean Aerochord & $6,6 \mathrm{~m}$ \\
\hline Lt & LTail & $\begin{array}{l}\text { Jarak antara Pesawat } \\
\text { dari wing body dan } \\
\text { Pesawat dari Tail }\end{array}$ & $24,8 \mathrm{~m}$ \\
\hline S & S & Wing Platform Area & $260 \mathrm{~m}^{2}$ \\
\hline St & STail & Tail Platform Area & $64 \mathrm{~m}^{2}$ \\
\hline \hline
\end{tabular}

Pesawat memiliki 5 Defleksi Control Surface (Primary Flight Control) yang masuk untuk melengkapi data yaitu sebagi berikut :

$$
\bar{u}=\left(\begin{array}{c}
\delta_{A} \\
\delta_{T} \\
\delta_{R} \\
\delta_{t h 1} \\
\delta_{t h 2}
\end{array}\right)=\left(\begin{array}{c}
u_{1} \\
u_{2} \\
u_{3} \\
u_{4} \\
u_{5}
\end{array}\right)=\left(\begin{array}{c}
\text { Aileron } \\
\text { Tail } \text { (Elevator) } \\
\text { Rudder } \\
\text { Throttle 1 } \\
\text { Throttle 2 }
\end{array}\right)
$$

Terdapat 9 simbol dari turunan Flat Earth yang mempengaruhi sikap dari suatu pesawat antara lain :

$$
\bar{x}=\left(\begin{array}{c}
u \\
v \\
w \\
p \\
q \\
r \\
\Phi \\
\theta \\
\psi
\end{array}\right)=\left(\begin{array}{c}
x_{1} \\
x_{2} \\
x_{3} \\
x_{4} \\
x_{5} \\
x_{6} \\
x_{7} \\
x_{8} \\
x_{9}
\end{array}\right)=\left(\begin{array}{c}
\text { velocity in body } x \text { axis } \\
\text { velocity in body } y \text { axis } \\
\text { velocity in body } z \text { axis } \\
\text { angular rate about body } x \text { axis } \\
\text { angular rate about body y axis } \\
\text { angular rate about body } z \text { axis } \\
\text { bank Euler angle } \\
\text { Pitch Euler angle } \\
\text { Yaw Euler angle }
\end{array}\right)
$$

Dari rumus diatas 3 simbol pertama merupakan translasi, 3 kedua merupakan rotasi dan 3 terakhir merupakan euler angle

Untuk membuat software pada MATLAB diperlukannya 10 langkah yang dapat dilakukan antara lain :

1. Control Limits/Saturation

2. Variabel Intermediate

3. Nondimensional Aerodynamic (Koefisien Force)

4. Aerodynamic force

5. Nondimensional Aerodynamic (Koefisien Momen tentang Aerodynamic Center)

6. Momen Aerodynamic terhadap Aerodynamic Center

7. Momen Aerodynamic terhadap Center of Gravity

8. Efek Propulsi

9. Efek Gravity

10. Explicit First Orderform 
Setelah Algoritma sudah dimasukkan semua, maka data tersebut dimasukkan kedalam Simulink dan dibuat block diagram seperti Gambar 2 dibawah ini :
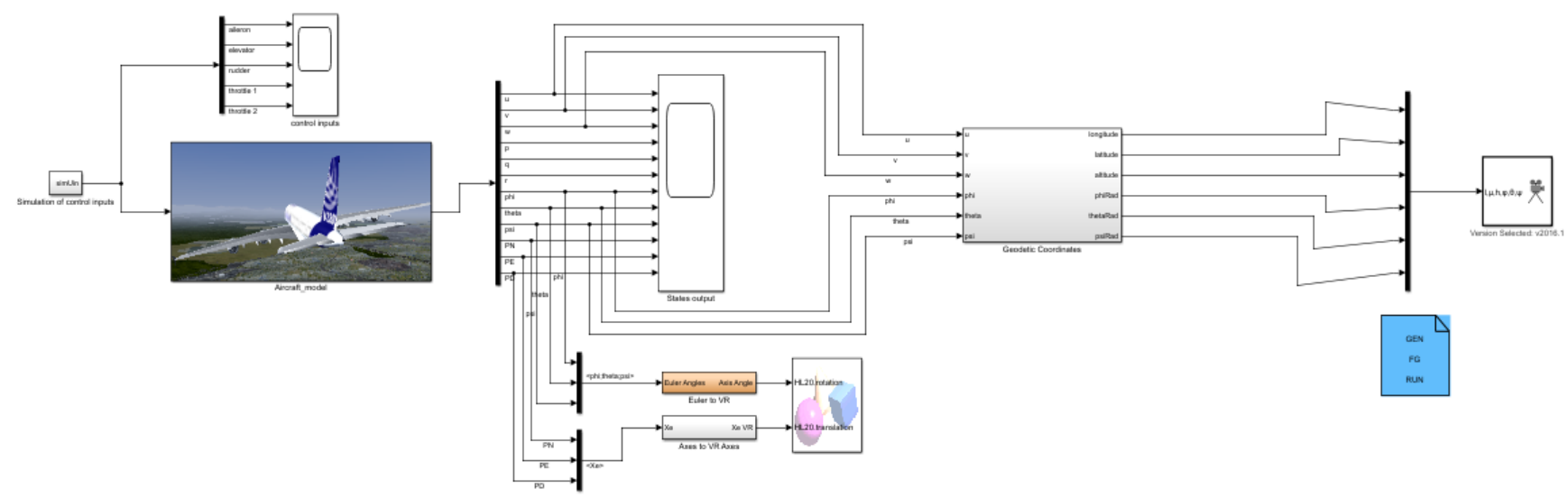

Gambar 2. Block Diagram RCAM

Dari block diagram diatas dapat terlihat bahwa ada 4 bagian yang terpisah yaitu, Control Input, State Output, Aircraft Model, dan Geodetic Coordinate. Gambar 2 dibawah ini merupakan isi dari beberapa bagian tersebut.

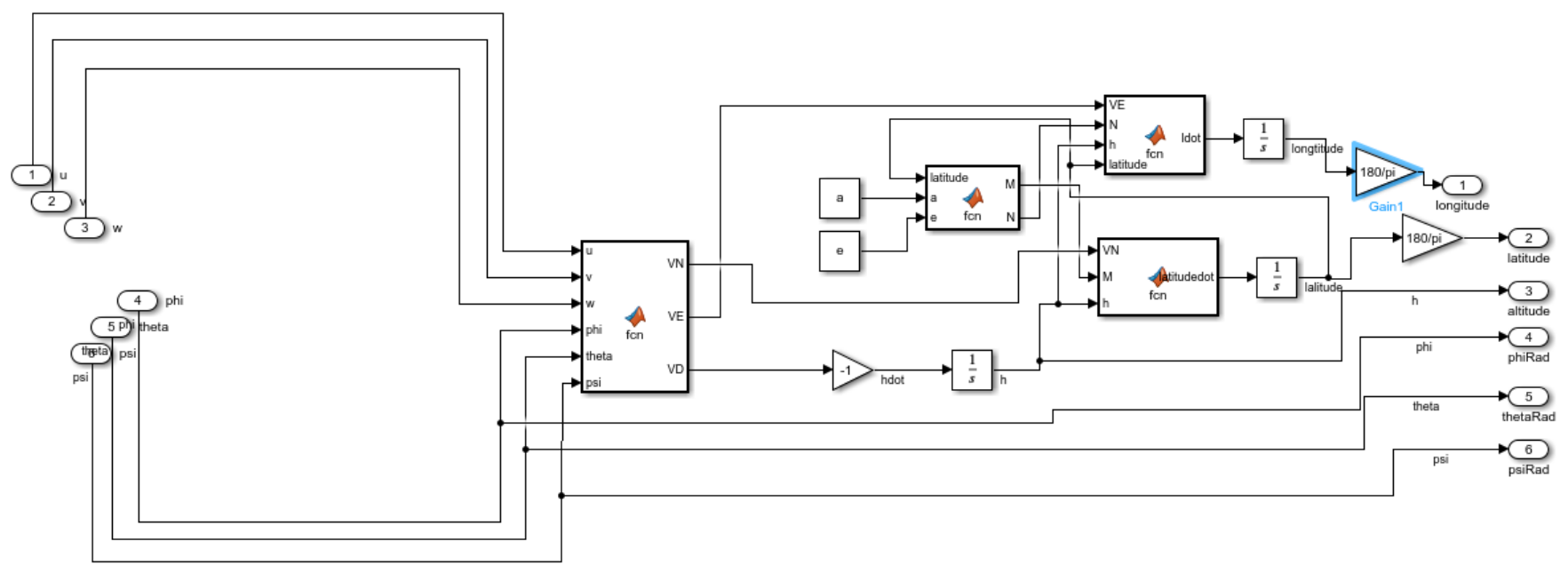

Gambar 3. Block Diagram Geodetic Coordinate 


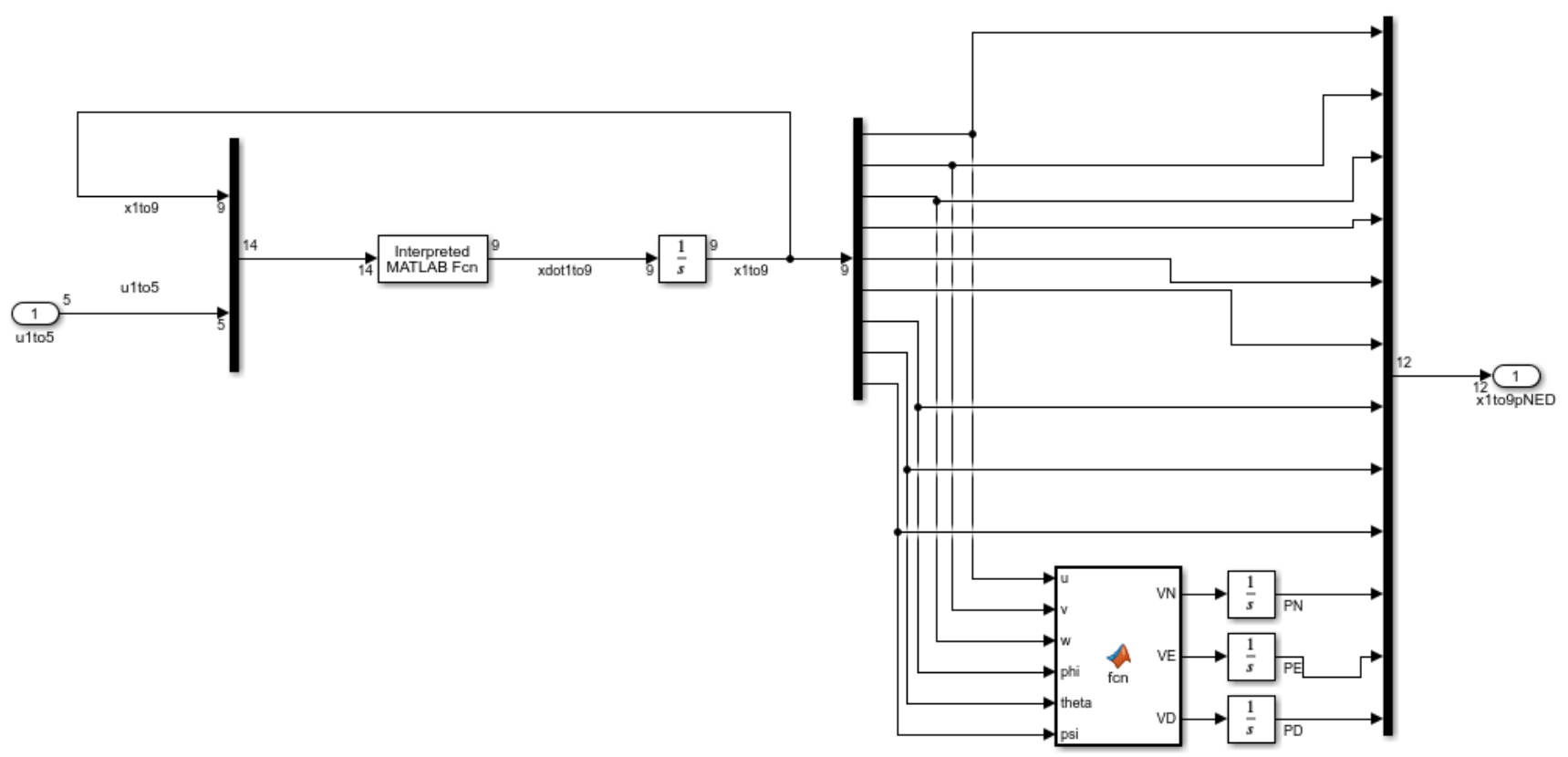

Gambar 4. Block Diagram Aircraft Model

Untuk Menganimasikan Simulink kedalam Animasi Simulink 3D, perlu adanya beberapa masukkan algoritma, seperti waktu yang dibutuhkan untuk menangkap data grafik. Setelah fungsi-fungsi pada block diagram telah disesuaikan dengan data dan masukkan yang ada selanjutnya hasil dari simulink di running kemudian akan memperlihatlkan animasi pesawat, grafik dari primary flight control, dan grafik dari States Output pesawat, dapat terlihat seperti gambar dibawah ini :

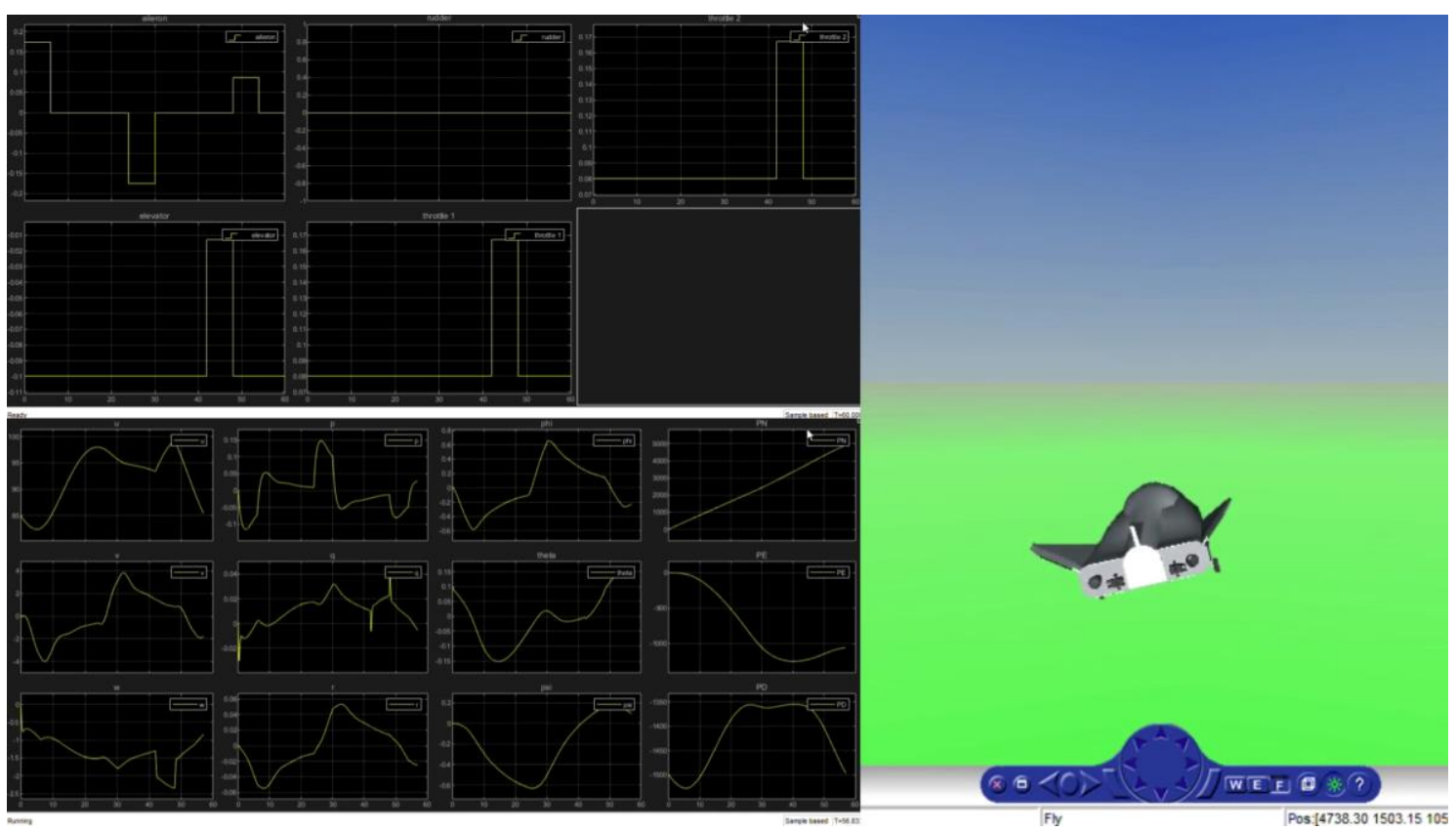

Gambar 5. Grafik Velocity in body $x$ Axis 
Hasil grafik yang ada pada simulasi bisa dianalisis stabilitasnya dengan membandingkan animasi pergerakan dari pesawat, grafik tersebut bisa terlihat seperti gambar dibawah ini :

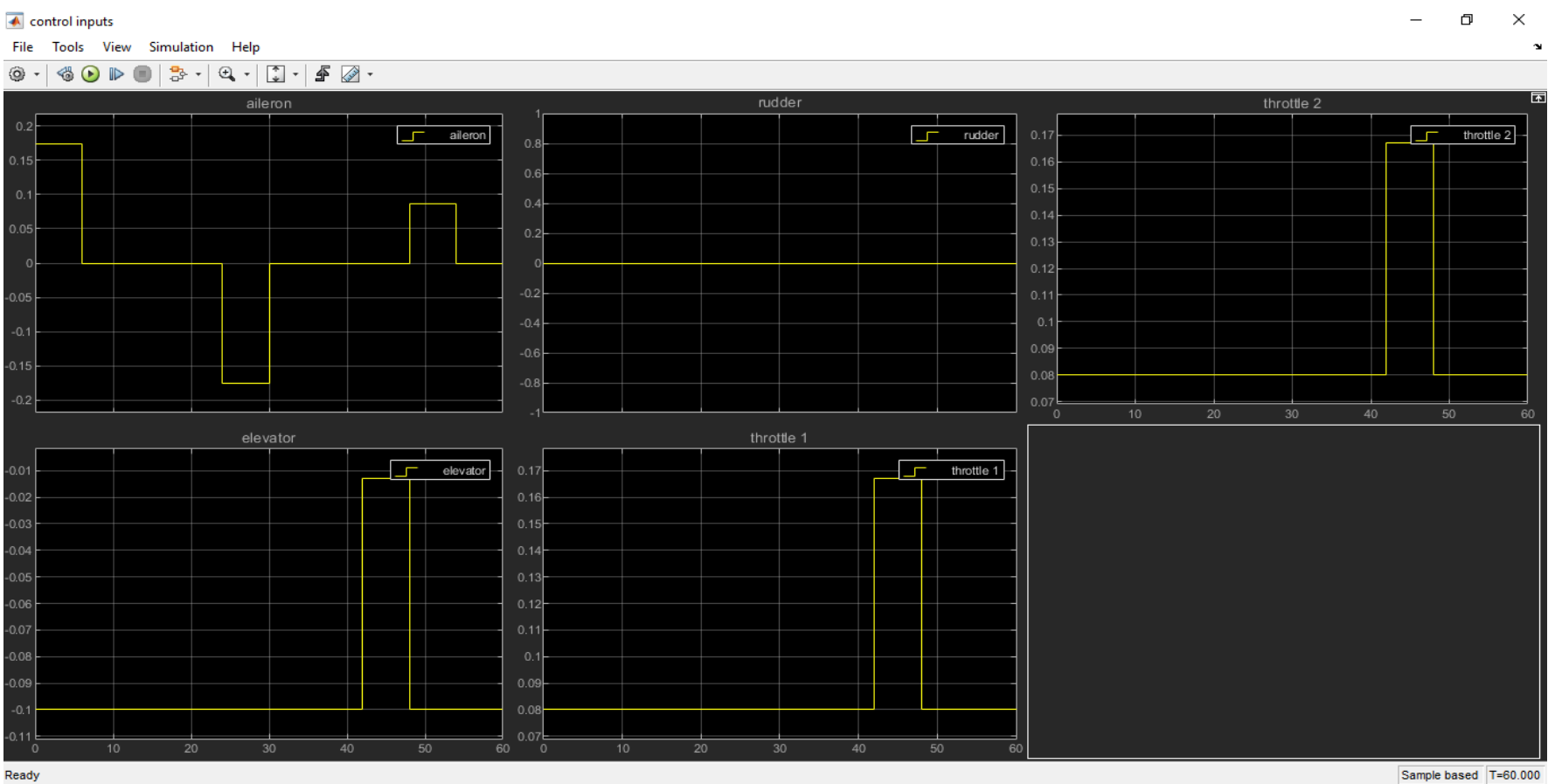

Gambar 6. Grafik Primary Flight Control

Dari grafik tersebut dapat dilihat bahwa Stabilitas elevator, rudder, aileron, dan throttle semuanya stabil dan sesuai dengan sikap dari animasi pesawat, pada aileron saat pesawat rolling (berguling) ke kiri grafik aileron naik, kalau pesawat rolling (berguling) ke kanan grafik aileron akan turun. Pada elevator, grafik terlihat sama seperti throttle 1 dan throttle 2 hal ini dikarenakan adanya hubungan gaya angkat dan gaya dorong, dibuktikan ketika gaya dorong dikurangi dan kecepatan berkurang maka gaya angkat akan lebih kecil dari berat (weight) pesawat dan pesawat akan turun dari ketinggiannya, jadi dapat disimpulkan ketika gaya angkat bertambah maka gaya dorong akan bertambah sejalan dengan gaya angkat. Untuk rudder grafik yang ada terlihat lurus, atau steady hal ini dikarenakan pergerakan dari pesawat tidak menunjukkan adanya pergerakan ke kanan atau kiri.

Berikut ini merupakan hasil output dari States output yang berisi factor-faktor yang mempengaruhi primary flight control, dapat dilihat seperti gambar berikut:

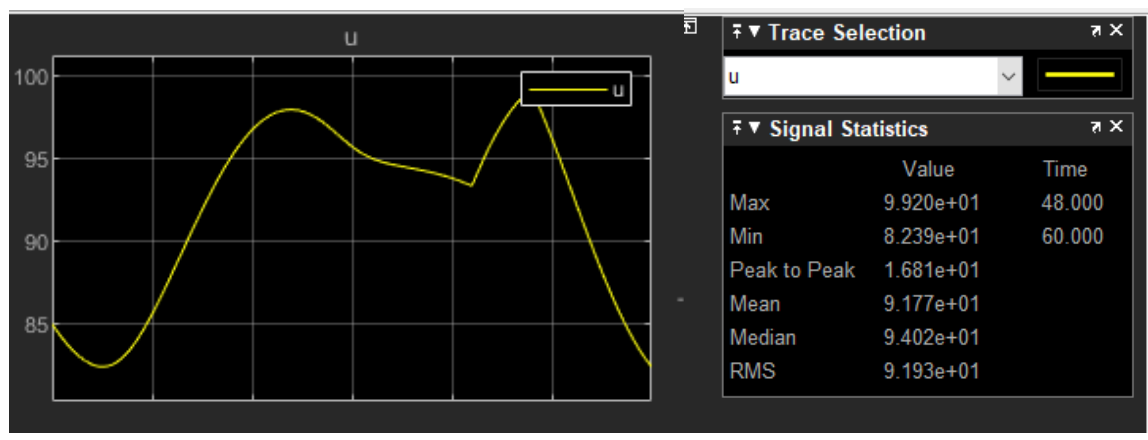

Gambar 7. Grafik Velocity in body x Axis 


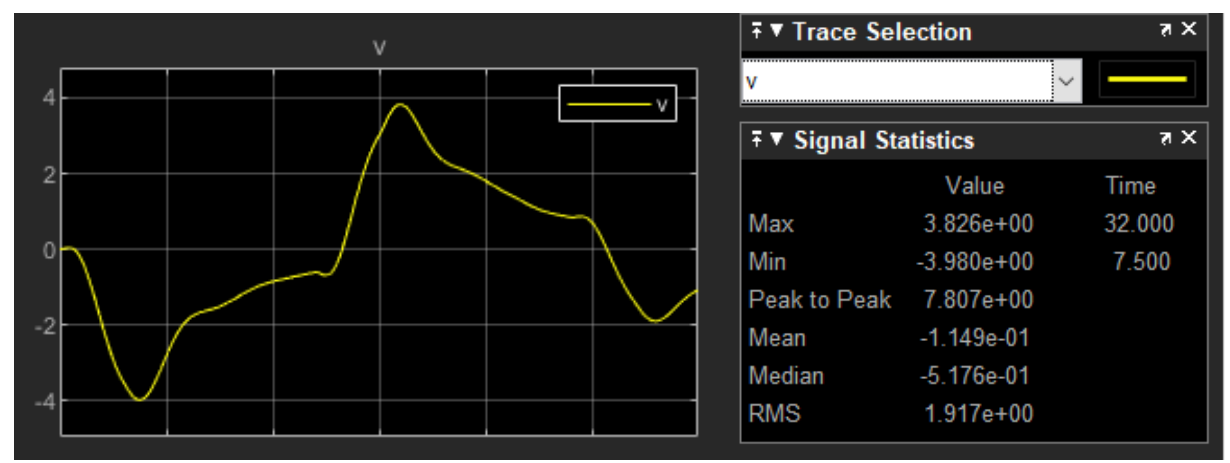

Gambar 8. Grafik Velocity in body y Axis

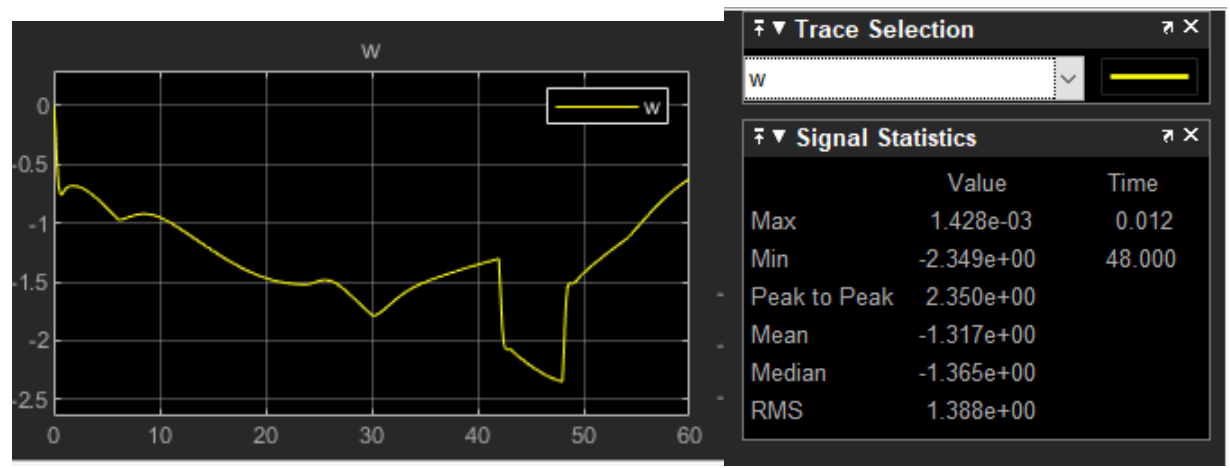

Gambar 9. Grafik Velocity in body z Axis

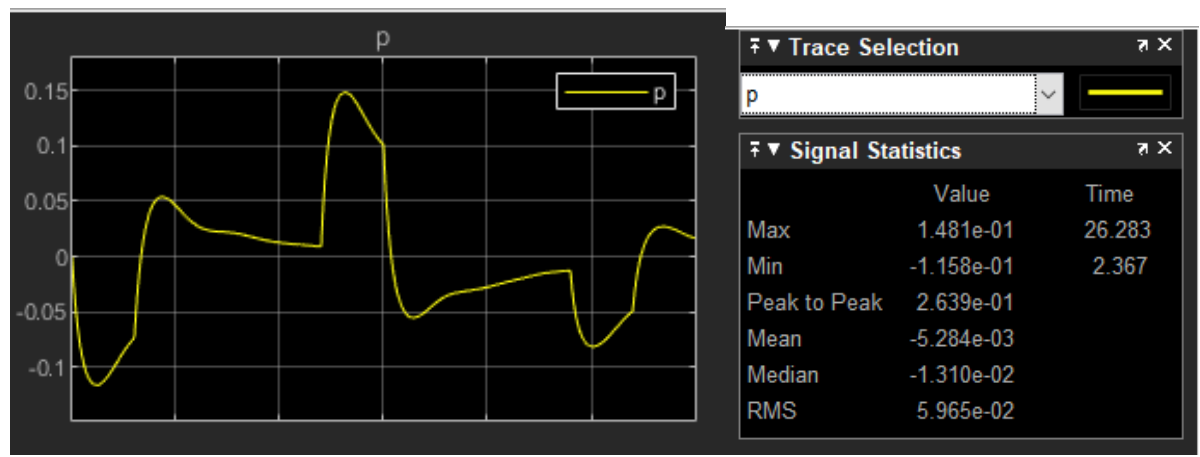

Gambar 10. Grafik Angular Rate About Body x Axis

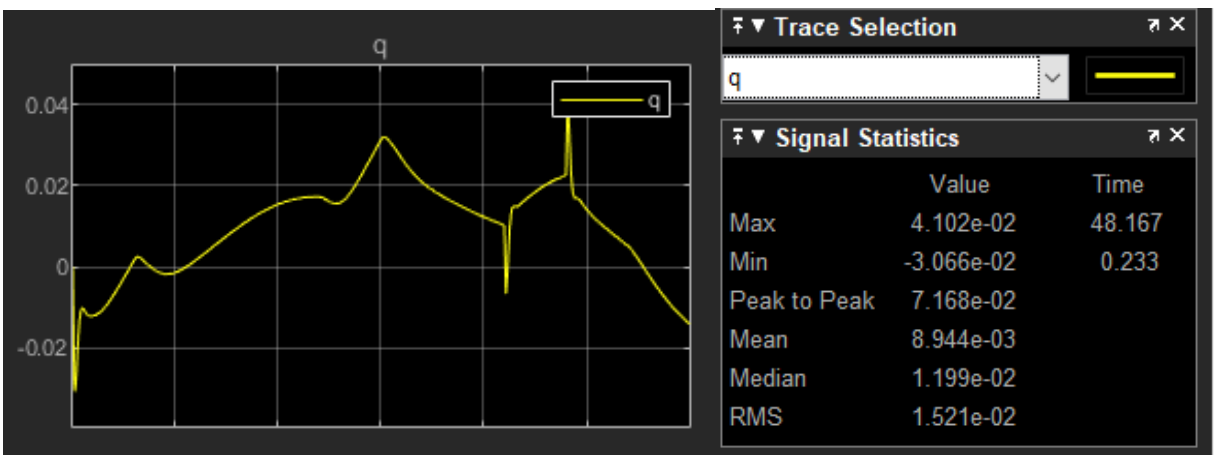

Gambar 11. Grafik Angular Rate About Body y Axis 


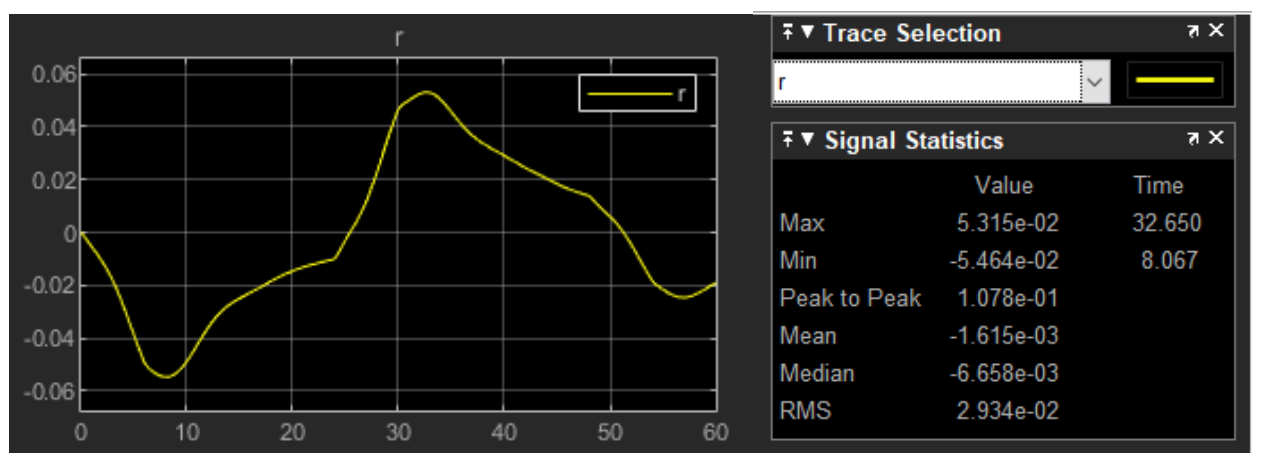

Gambar 12. Grafik Angular Rate About Body z Axis

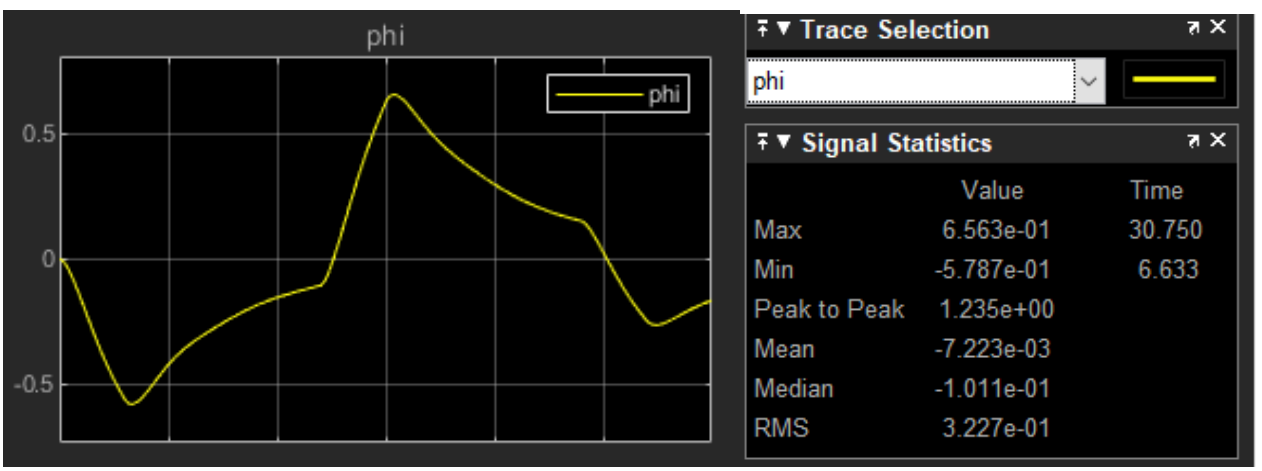

Gambar 13. Grafik Bank Euler Angle
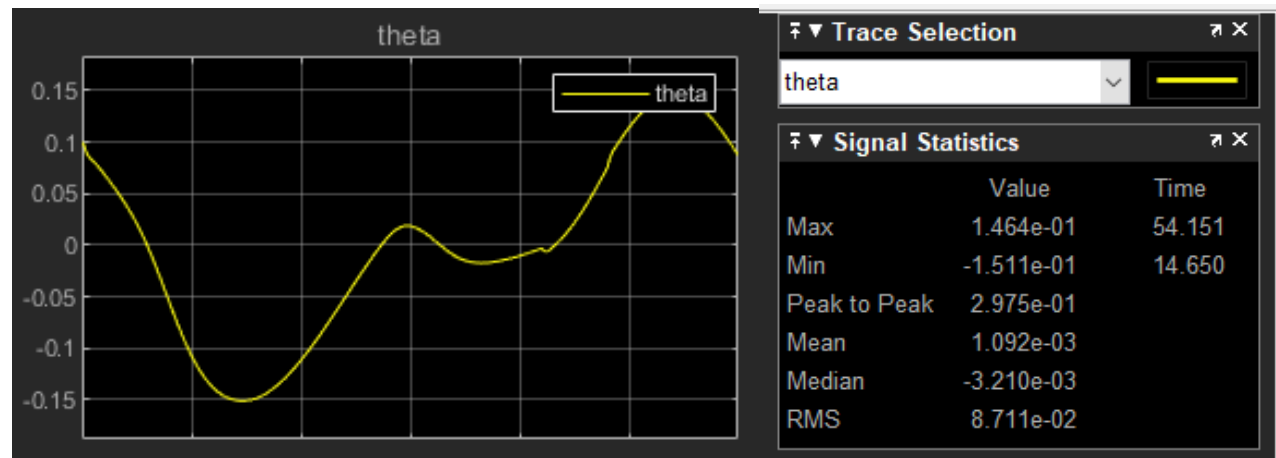

Gambar 14. Grafik Pitch Euler Angle

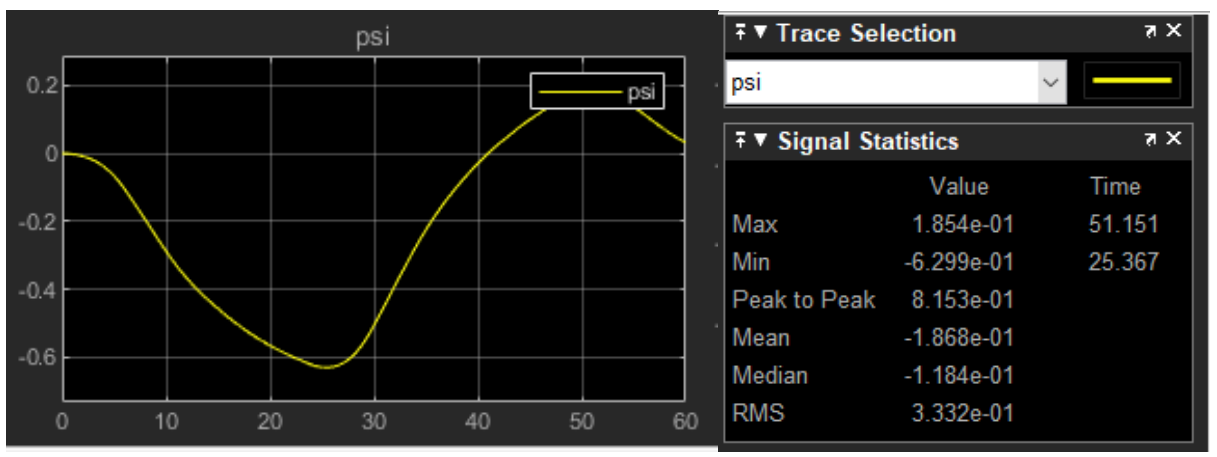

Gambar 15. Grafik Yaw Euler Angle

Prosiding Seminar Nasional Sains Teknologi dan Inovasi Indonesia - Akademi Angkatan Udara Volume 3, Tahun 2021: hlm. 11-22 


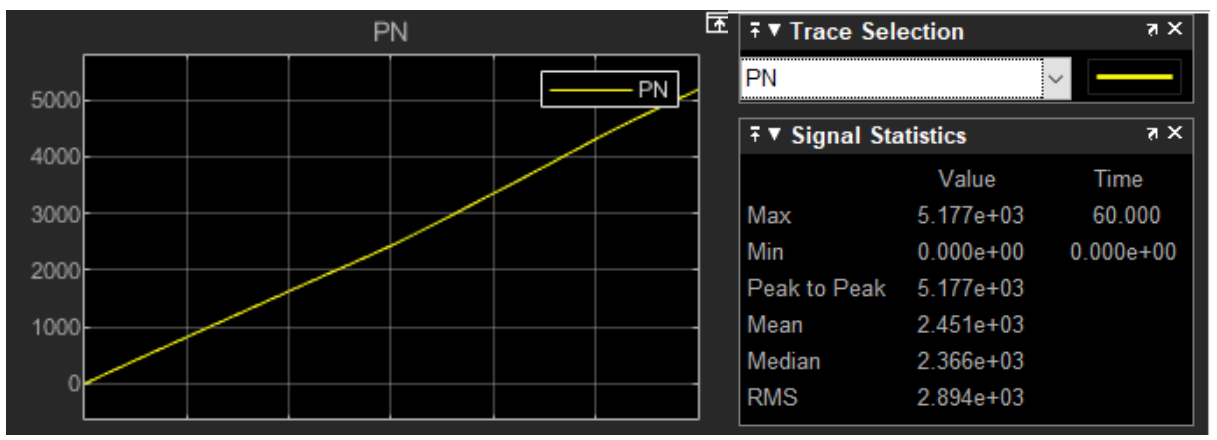

Gambar 16. Grafik Posisi North
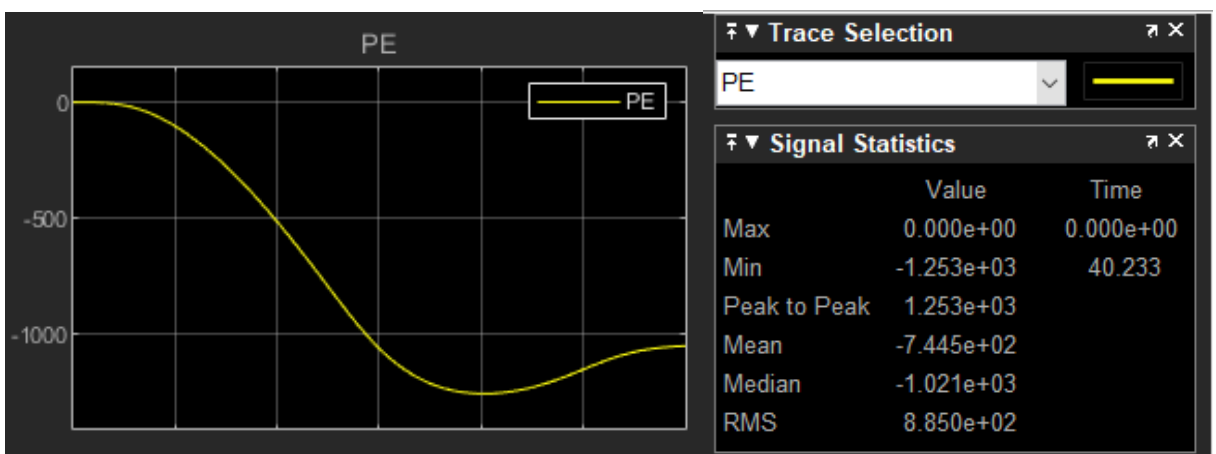

Gambar 17. Grafik Posisi East

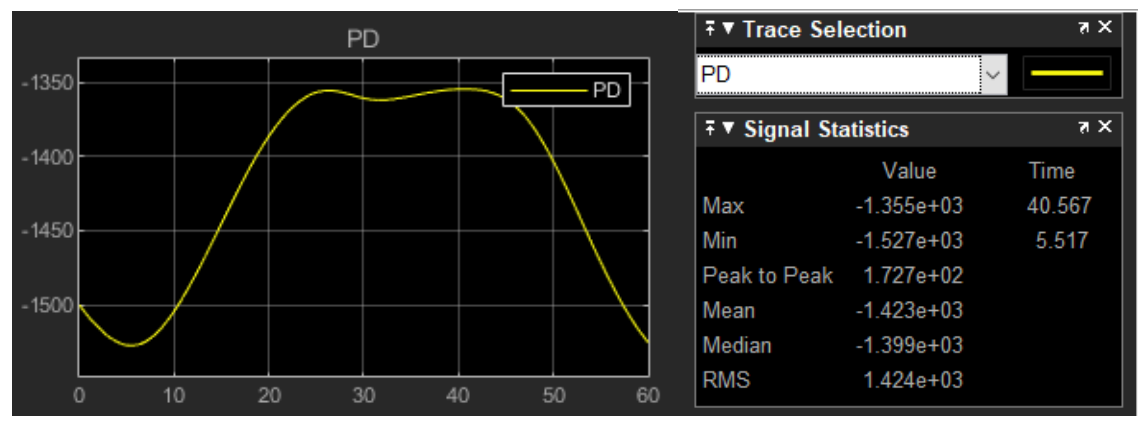

Gambar 18. Grafik Posisi Down

Dari Hasil Grafik Diatas dapat terlihat bahwa Stabilitas dari keadaan pesawat baik dan sesuai dengan pergerakan animasi pesawat, dan sesuai dengan sumbu-sumbu yang bekerja pada pesawat.

\section{KESIMPULAN}

Berdasarkan hasil Analisa terhadap RCAM (Research Civil Aircraft Model), model pesawat tersebut sudah berhasil dilakukan dengan menggunakan Bahasa pemrograman MATLAB. Hasil dari RCAM yang telah dibuat yaitu berupa grafik. Grafik yang dihasilkan dari running Simulink sesuai dengan pergerakan dari animasi pesawat. Karena dalam hasil Animasi pesawat tersebut 
dapat juga diarahkan dengan kursor maka untuk Pengembangan selanjutnya bisa digunakan Joystick agar lebih mudah untuk mengontrol animasi pesawat tersebut.

\section{UCAPAN TERIMA KASIH}

Ucapan terima kasih kami sampaikan kepada pihak pihak yang telah berkontribusi dalam penelitian ini hingga makalah ini dapat di publikasikan pada Seminar Nasional Sains Teknologi dan Inovasi Indonesia 2021, diantaranya kepada:

a. LPDP (Lembaga Pengelola Dana Pendidikan) sebagai sponsor penelitian.

b. BRIN (Badan Riset dan Inovasi Nasional) sebagai penyedia prasarana penelitian.

c. Universitas Nurtanio sebagai penyedia prasarana penelitian.

d. AAU (Akademi Angkatan Udara) sebagai penyelenggara konferensi dan prosiding.

e. Serta rekan rekan - rekan peneliti lainnya.

\section{REFERENSI}

[1] D. Moormann, A. Varga, G Looye, and Grubel. Robustness Analysis Applied to Autopilot Design Part 3: Physical Modeling of aircraft for automated LFT generation applied to the Research Civil Aircraft Model, 1998

[2] P. Lembrechts, S. Bennani, G. Looye, and A. Helmersson. GARTEUR Open : Robust Flight Control Design Challenge Manual, GARTEUR, 1997

[3] Cristopher Lum. A nonlinear, 6 DOF Dynamis Model on Aircraft, 2020

[4] Mochamad Safarudin, Pengenalan Matlab dan Simulink, 2017

[5] Resi Arumin Sani, Erna Apriliani, dan Mohammad Isa Irawan. Estimasi Variabel Keadaan Gerak Longitudinal Pesawat Terbang Menggunakan Metode Fuzzy Kalman Filter,2016

[6] Simulink 3D Animation, https://www.mathworks.com/products/3d-animation.html 